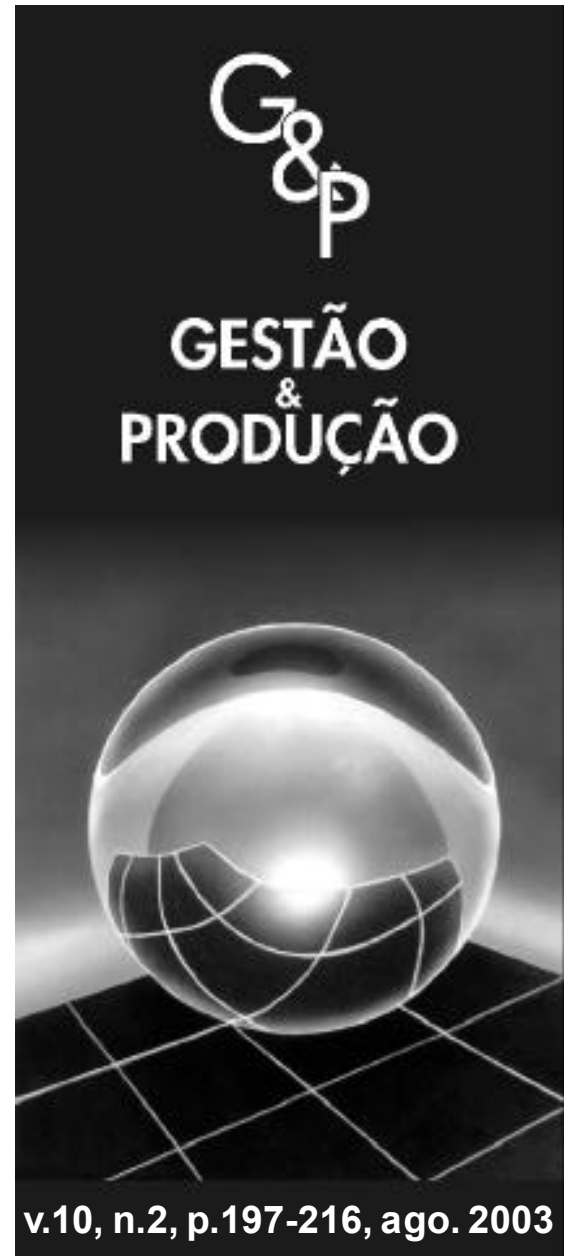

\title{
A INFLUÊNCIA DO DEPARTAMENTO DE PÓS-VENDAS NA RETENÇÃO DE CLIENTES: UM ESTUDO QUALITATIVO EM UMA EMPRESA DE MEDICINA DE GRUPO
}

\author{
Gabriel Sperandio Milan \\ José Luis Duarte Ribeiro \\ LOPP/PPGEP/UFRGS, \\ Praça Argentina, 9, CEP 90040-020, \\ Porto Alegre, RS, Brasil, \\ e-mails: ribeiro@ufrgs.br, gabmilan@ppgep.ufrgs.br
}

Recebido em 29/7/2002

Aceito em 13/6/2003

\section{Resumo}

O presente trabalho apresenta uma pesquisa qualitativa desenvolvida no ambiente de uma empresa de medicina de grupo, no intuito de levantar subsidios para análise e interpretação do retorno proporcionado pela implementação do Departamento de Pós-Vendas para a empresa. Assim, objetivouse identificar a influência da prática desse departamento sobre a retenção de clientes, verificar se estes percebem as ações do Departamento de Pós-Vendas como um investimento no relacionamento pelo provedor de saúde e entender se tal investimento pode incrementar o compromisso e a confiança do cliente em relação ao provedor de saúde, reforçando sua permanência (retenção) no relacionamento. Para alcançar os objetivos propostos pelo trabalho, no que tange à utilização do método qualitativo, foram realizadas entrevistas individuais com clientes da organização, as quais são descritas, analisadas e interpretadas.

Palavras-chave: pós-vendas, retenção de clientes, relacionamento, pesquisa qualitativa.

\section{Introdução}

$\mathrm{E}$

m um mercado cada vez mais competitivo, as empresas devem adotar estratégias para obter vantagem competitiva sustentável (Porter, 1989; Hunt et al., 2002). Assim, o marketing de relacionamento, conjugado à estratégia de retenção de clientes, torna-se uma alternativa 
atraente. Dependendo do setor de atuação, as empresas podem aumentar seus lucros de $25 \%$ a $85 \%$, reduzindo em apenas $5 \%$ a perda de clientes (Reichheld \& Sasser Jr., 1990). Segundo Asbrand (1997) e Knowles (1997), a retenção pode custar 4 a 8 vezes menos do que a aquisição de clientes.

A taxa de retenção de clientes é vista por Rust \& Zahorik (1993) como o componente mais importante para que a empresa consolide sua participação no mercado, sendo direcionada pela satisfação do cliente. Embora a satisfação de clientes não seja obrigatoriamente revertida em sua lealdade, as empresas devem persegui-la e reconhecer que ela é alcançada pela entrega consistente de valor superior ao cliente (Reichheld, 1993; Reichheld et al., 2000).

Do ponto de vista estratégico, a atração de novos clientes deveria ser considerada um passo intermediário, uma vez que o fundamental é desenvolver relacionamentos estreitos com os clientes atuais, objetivando sua lealdade (Berry, 2002). Os benefícios dessa lealdade geralmente se refletem nos motivos pelos quais um competidor é mais lucrativo que outro (Reichheld, 1993). É imprescindível que todos os colaboradores entendam o valor dos clientes ao longo do tempo, almejando a perda zero de clientes (Reichheld \& Sasser Jr., 1990).

Nesse sentido, o marketing de relacionamento surgiu como forma de obtenção de vantagem competitiva, entendendo seu conceito como atrair, manter e aumentar os relacionamentos com clientes (Berry, 2002) e, quando necessário, terminá-los (Grönroos, 2000). Há profunda mudança de paradigma implícita no conceito - da visão que aborda o marketing transacional, focado na venda como um fim em si mesma, para o marketing relacional, focado em relacionamentos de longo prazo com os clientes (Dwyer et al., 1987; Morgan \& Hunt, 1994; Gummesson, 1998).

As atividades de pós-vendas estão sendo valorizadas e incorporadas aos negócios, pois são uma prática de marketing cujo foco é a retenção de clientes, em que o grande desafio é reconhecê- los, mostrando-lhes o quanto a empresa os estima por terem lhe conferido a preferência (Vavra \& Pruden, 1995). Vavra (1994) afirma que, quanto mais tempo se mantém um cliente, mais lucrativo ele poderá ser para o negócio, e por quanto mais tempo o cliente comprar de uma mesma organização, mais dependente poderá se tornar de seus produtos ou serviços, e estará menos suscetível a ofertas com preços mais baixos da concorrência.

Portanto, programas voltados à criação de valor para a retenção de clientes, como as atividades pós-vendas, devem responder às necessidades específicas de cada cliente, logicamente observando sua viabilidade econômico-financeira. De acordo com Rust et al. (2001), esse tipo de programa deve maximizar a probabilidade de o cliente retornar para futuras compras, ou maximizar a magnitude dessas futuras compras, ou, ainda, minimizar a probabilidade de o cliente comprar de um concorrente.

Vale observar que a retenção de clientes ou, de forma mais geral, a satisfação de clientes, é um tema intensamente investigado na área da Engenharia de Produção. Por exemplo, no último Encontro Nacional de Engenharia de Produção (ENEGEP 2002), 64 artigos mencionavam a importância da satisfação dos clientes, sendo que 10 artigos tinham a satisfação de clientes como tema principal (Campos \& Ramos, 2002; Souza et al., 2002; Dahmer \& Estrada, 2002; Salomi \& Miguel, 2002; Nascimento et al., 2002; Souza, 2002; Souza \& Silva, 2002; Glasenapp et al., 2002; Pinheiro \& Godoy, 2002; Hermosilla et al., 2002).

\section{Caracterização da empresa}

A empresa em estudo é uma operadora de planos de saúde com atuação local e está focada no segmento de Plano de Saúde Empresarial, sendo classificada na modalidade medicina de grupo. Contextualizando sua estrutura, a empresa faz parte de um grupo da área da saúde, o qual é constituído por cinco unidades de negócio: Plano de Saúde, Hospital, Unidade de Medicina do Trabalho, Laboratório e Farmácia. 
O Grupo surgiu com a fundação do Hospital no ano de 1957, com o objetivo de oferecer serviços hospitalares demandados pelo crescimento do mercado local, pois a rede hospitalar existente na época não atendia às expectativas da comunidade. Pela necessidade dos empresários em romper com o monopólio na área da saúde privada, no segmento empresarial, o Grupo estruturou-se e criou, em 1988, o Plano de Saúde, facilitado pela verticalização dos serviços. Em razão da parceria e do apoio dos empresários locais, iniciou suas atividades com uma estratégia de posicionamento bem definida, atendendo aos colaboradores de seus clientes-empresa.

Sua base de clientes é composta por 53.235 usuários, dos quais 39.003 são provenientes do Plano Empresarial, distribuídos entre 1.590 empresas, representando $73,27 \%$ do total de clientes, enquanto os usuários do Plano Pessoal (individual ou familiar) são 14.232 , representando $26,73 \%$ do total de clientes, conforme apresentado na Tabela 1.

Com as exigências de coberturas impostas pela Nova Regulamentação (Lei 9.656/98), a iniciativa privada ainda não possui o real dimensionamento em relação à demanda potencial em casos de transplantes (de córnea e rins), cardiopatias e doenças degenerativas. Com isso, as organizaçõos devem preparar suas estruturas a fim de suportar tais coberturas com o nível de qualidade desejado pelo mercado, em conseqüência da tendência de aumento nos custos, reforçada pela atualização tecnológica exigida pela medicina, o reaparecimento de doenças erradicadas e o surgimento de novas doenças.

Além disso, há a forte pressão da concorrência, que limita os preços de venda e os ajustes nos preços, restringindo o aumento das receitas que deveriam fomentar os investimentos necessários. Isso leva a empresa a adotar uma postura agressiva na área comercial, enfocando a retenção de clientes para, posteriormente, aumentar o número de clientes, diluindo seus custos fixos.

\section{O Departamento de Pós-Vendas da empresa}

Como arcabouço teórico para a fundamentação conceitual do Departamento de PósVendas, quanto ao projeto e sua implementação, foi utilizada a filosofia proposta pelo marketing de relacionamento, a qual prevê trocas relacionais de longo prazo e comunicação permanente entre o prestador de serviços e seus clientes-empresa, conjugada à estratégia de retenção de clientes e ao desenvolvimento de sua lealdade (Milan, 2002).

Para melhor entendimento da forma de atuação da equipe, são resgatados os objetivos do Departamento de Pós-Vendas e sua operacionalização e inserção na estrutura funcional, mais especificamente na Área Comercial da empresa.

Tabela 1 - Matriz de clientes.

\begin{tabular}{cccc}
\hline Tipo de cliente & Número de clientes & Número de empresas & $\mathbf{\%}$ \\
\hline Empresarial & 39.003 & 1.590 & 73,27 \\
Pessoal & 14.232 & - & 26,73 \\
Total & 53.235 & 1.590 & 100,00 \\
\hline
\end{tabular}

Fonte: Relatório de Clientes (dezembro de 2001). 


\subsection{Objetivos do Departamento de Pós-Vendas}

Os principais objetivos estabelecidos para o Departamento de Pós-Vendas em sua implementação foram:

1. Estabelecer contatos com clientes-empresa no intuito de fortalecer um relacionamento de longo prazo, buscando sua retenção.

2. Consolidar a imagem e a amplitude do mix de serviços da empresa.

3. Detectar pontos fortes e fracos (âmbito interno da empresa) e oportunidades e ameaças (âmbito externo) em relação ao cliente e ao mercado, encaminhando para as áreas responsáveis tomarem as devidas providências.

4. Auxiliar na organização, agendamento e operacionalização das atividades do Grupo de Prevenção com os clientes.

5. Encaminhar documentação relativa a reclamações de clientes para a gerência responsável da área, bem como, quando possível, retornar ao cliente quais medidas foram adotadas.

6. Dirimir dúvidas para o cliente (empresas) e usuários (funcionários), antecipando-se ao surgimento de possíveis problemas, dentro de uma conduta pró-ativa.

7. Sensibilizar e estimular os clientes a solicitarem propostas de serviços prestados pela empresa e que ainda não possuem, encaminhando-os para o Departamento de Vendas.

8. Levantar e registrar os motivos que causam a deserção de clientes.

9. Levantar sugestões para novos serviços.

\subsection{Operacionalização do Departamento de Pós-Vendas}

A equipe de Pós-Vendas desenvolve um programa periódico de visitas à atual carteira de clientes em caráter pró-ativo, estabelecendo estreito relacionamento com os mesmos, refor- çando o posicionamento da marca (imagem institucional), bem como dos serviços ofertados, e despertando o interesse para o crescimento e desenvolvimento das relações existentes.

As atividades são intimamente relacionadas à atuação das gerências, uma vez que as informações registradas e encaminhadas aos responsáveis devem se tornar uma das diversas fontes para fomentar mudanças em processos que visem à melhoria contínua no atendimento aos clientes.

\subsection{A inserção do Departamento de Pós-Vendas na estrutura funcional}

O Departamento de Pós-Vendas está subordinado à Área Comercial da empresa, juntamente com o Departamento de Vendas (internas e externas), pela qual responde o Gerente Comercial, conforme apresentado na Figura 1.

\section{Estabelecimento do problema e objetivos da pesquisa}

A implementação do Departamento de PósVendas gerou para a empresa a oportunidade de analisar, sob a percepção dos clientes, o nível de atendimento prestado pela equipe e os resultados efetivos em relação à sua verdadeira influência para o alcance do principal objetivo proposto, ou seja, para o fortalecimento de relacionamentos de longo prazo e para a retenção de clientes.

Assim, o foco central desta pesquisa qualitativa é investigar o relacionamento cliente-provedor de saúde, considerando três objetivos distintos:

1. Identificar a percepção dos clientes quanto à influência da prática do Departamento de Pós-Vendas sobre a retenção de clientes (ou o desejo futuro dos clientes em permanecerem engajados no relacionamento com o atual provedor de saúde).

2. Verificar se os clientes percebem as ações do Departamento de Pós-Vendas como um investimento no relacionamento, sob uma ótica de longo prazo, por parte do provedor de saúde. 


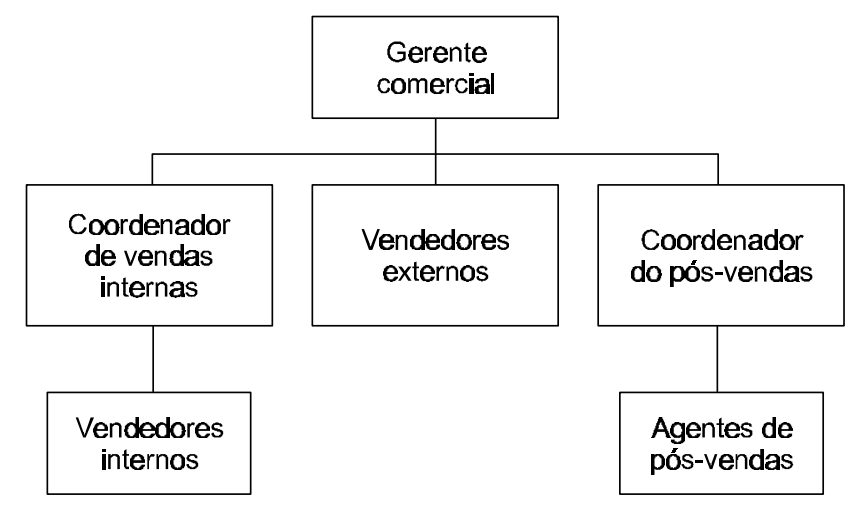

Figura 1 - Organograma da Área Comercial.

3. Entender se tal investimento no relacionamento, quando percebido, pode incrementar o compromisso e a confiança do cliente em relação ao provedor de saúde, reforçando sua retenção.

\section{Método da pesquisa}

Enquanto as técnicas quantitativas focam coisas que possam ser contadas, utilizando categorias predeterminadas que podem ser tratadas como dados internos ou ordinários e sujeitos à análise estatística, as técnicas qualitativas focam a experiência das pessoas e seu respectivo significado em relação a eventos, processos e estruturas, inseridos em cenários sociais (Skinner et al., 2000).

A pesquisa qualitativa utiliza amostras pequenas e estatisticamente não-representativas, tendo por principais objetivos: ajudar a refinar conceitos, conhecer reações gerais, aprender a linguagem do cliente ou explorar novas áreas de oportunidade (Hellebusch, 2000). As metodologias qualitativas procuram explicar situações particulares e devem fornecer conclusões específicas para o caso em estudo (Hyde, 2000).

A base para a generalização em estudos qualitativos é a analítica, proposta por Yin (1994), em que o objetivo do pesquisador deve ser o de expandir e generalizar teorias, e não o de estabelecer a freqüência e a probabilidade nas quais um fenômeno pode ocorrer em determinada população (Hyde, 2000). Portanto, o principal benefício da pesquisa qualitativa é entender os motivos e as razões dos entrevistados em relação às suas respostas, uma vez que tais informações são, virtualmente, impossíveis de capturar com tal profundidade em pesquisas quantitativas (Hellebusch, 2000).

A fim de identificar as percepções dos clientes em relação aos objetivos propostos para o estudo, utilizou-se o método indutivo, por meio de entrevistas individuais em que o pesquisador inicia com observações específicas e procura estabelecer generalizações sobre o fenômeno investigado (Hyde, 2000).

Para que os objetivos do estudo pudessem ser maximizados, foi abordado somente o segmento Plano Empresarial, denotando o relacionamento business-to-business (B2B). O público-alvo da pesquisa foi constituído por 1.590 empresas, e a escolha da amostra foi fundamentada em dois aspectos: 1. as atividades desenvolvidas pelo Departamento de Pós-Vendas são direcionadas ao relacionamento com o segmento Empresarial; e 2. a representatividade desse segmento sobre o total da carteira de clientes da empresa. 
Para que a coleta de dados fosse segmentada, resgataram-se os critérios de classificação de clientes utilizados pela empresa quanto ao porte dos mesmos, como pode ser observado na Tabela 2. A seleção das empresas respeitou o critério de identificação por conveniência, por meio de uma lista quíntupla de clientes em cada categoria (A, B e C), e a partir dela foi selecionado um de cada categoria, aleatoriamente.

Quanto aos participantes, ou melhor, à pessoa que seria entrevistada, representando cada clienteempresa selecionado, observaram-se alguns critérios quanto ao seu perfil: 1. estar inserida no processo de negociação e/ou decisão da contratação do atual convênio de plano de saúde; 2 . estar em contato com expressivo número de colaboradores de sua empresa (entenda-se usuários do Plano de Saúde), os quais transmitem suas percepções quando da utilização dos serviços do convênio; e 3. exercer função ou cargo que lhe confira liberdade de expressão quanto aos aspectos abordados pela pesquisa.

No intuito de coletar informações com a maior profundidade possível, as entrevistas foram aplicadas, para cada entrevistado, em duas sessões, momentos estes denominados Sessão 1 e Sessão 2, apresentando tempo médio de duração de duas horas para cada sessão.

Para maior detalhamento dos objetivos que permearam cada sessão, segue o Quadro 1. Cada encontro levou em consideração um roteiro predefinido de questões, conforme consta no Anexo A. Na Sessão 1, os entrevistados também foram questionados a respeito da história e das características da empresa.

Cabe ressaltar que, no início da primeira sessão, foi realizada breve explanação dos objetivos do estudo e de como este seria desenvolvido, assegurando a cada participante total sigilo e anonimato em relação às suas colocações.

Tabela 2 - Classificação de clientes-empresa quanto ao seu porte.

\begin{tabular}{ccc}
\hline \multicolumn{1}{c}{ Perfil dos clientes } & Número de empresas & $\mathbf{\%}$ \\
\hline $\mathbf{A}$ - acima de 201 usuários & 23 & 1,45 \\
$\mathbf{B}-$ de 51 até 200 usuários & 95 & 5,97 \\
$\mathbf{C}-$ com até 50 usuários & 1.472 & 92,58 \\
Total & 1.590 & 100,00 \\
\hline
\end{tabular}

Fonte: Relatório Curva A/B/C de Clientes (dezembro de 2001)

Obs: O critério utilizado pela empresa para classificar os clientes-empresa provenientes do Plano Empresarial é o número de usuários por empresa.

\section{Quadro 1 - Número de sessões e objetivos.}

\begin{tabular}{cl}
\hline Sessões & \multicolumn{1}{c}{ Objetivos de cada sessão } \\
\hline 1 & $\begin{array}{l}\text { Contextualizar a pesquisa para os entrevistados, levantar e registrar dados de forma a não } \\
\text { inibir suas considerações, as quais servirão para consolidar ou reformular o Roteiro de } \\
\text { Questões a ser aplicado na Sessão } 2 .\end{array}$ \\
& $\begin{array}{l}\text { Consolidar e ampliar a coleta de dados por meio da aplicação ordenada do Roteiro de } \\
\text { Questões. }\end{array}$ \\
\hline
\end{tabular}




\section{Descrição das entrevistas}

A fim de coletar subsídios para posterior análise e interpretação dos dados quanto aos objetivos propostos pelo trabalho, segue a descrição das três entrevistas individuais realizadas com clientes, contendo as observações mais relevantes.

\subsection{Cliente A}

\subsubsection{Identificação do cliente e entendimento do convênio}

O entrevistado é o Gerente de Recursos Humanos de uma empresa do setor moveleiro, exercendo o papel de negociador nos processos de contratação de benefícios para seus colaboradores. Trata-se de uma empresa fundada em 1983, com atuação nos segmentos de móveis e divisórias para escritório. Além do mercado nacional, exporta seus produtos para outros três países do Mercosul: Argentina, Paraguai e Uruguai.

O processo de negociação e decisão pela manutenção do atual convênio ocorreu por meio da análise de preços, abrangência de coberturas e benefícios, bem como das necessidades de seus colaboradores e das ofertas dos demais concorrentes. Para o entrevistado, o processo de negociação entre as empresas sempre foi caracterizado pelo diálogo, citando o exemplo do último reajuste contratual, quando foram previamente visitados, e o reajuste de preços definido em conjunto.

\subsubsection{Aspectos valorizados, pontos fortes e fracos}

Atribuindo alto valor ao processo de negociação, comentou: "realmente, não apenas a empresa é o cliente, mas também os funcionários, os quais são os usuários do Plano. Temos a idéia de sempre envolver as pessoas (funcionários) em qualquer processo de negociação, para qualquer tipo de prestador de serviços".

Os aspectos mais valorizados em relação ao provedor de saúde são: qualidade do atendimento prestado, rapidez e atenção no atendimento, cumprimento do que fora contratado e retorno às solicitações encaminhadas. $\mathrm{O}$ entrevistado destacou: "a empresa busca no fornecedor para a saúde, não apenas uma relação baseada em valores, mas uma visão de todo. Temos um grupo diferenciado de funcionários (nível salarial e formação educacional) em relação à maioria das empresas. Eles têm uma expectativa mais exigente, são mais críticos, por isso, a qualidade na prestação de serviços, como um todo, é fundamental, o que até justificaria pagar mais por um nível de serviços diferenciado".

Poucas dúvidas são geradas na utilização dos serviços. Para o entrevistado, a Nova Regulamentação e o fato de os planos de saúde não serem mais novidade fazem com que os serviços pareçam bastante padronizados no mercado. Dentre as dúvidas que surgem, estão aquelas relacionadas a aspectos operacionais, principalmente no que diz respeito à cobrança de diferenças em exames.

Por outro lado, o entrevistado identificou como pontos fortes do convênio: "facilidade em negociar, acrescentando que os reajustes nos valores são negociados e não impostos; relação custo-benefício; limpeza e nível de informações no hospital; atendimento de forma geral; ambulatório; farmácia (atendimento e horários); e imagem corporativa (para quem já possui convênio com o Plano)".

Como pontos fracos, relatou: "atendimento do SPAR - Setor de Pré-Internação de Alta Resolubilidade - junto ao hospital (relação entre tempo de espera para diagnóstico e encaminhamento do cliente); número de médicos nas especialidades gastroenterologia e otorrinolaringologia; demora no agendamento de consultas (em algumas especialidades); cumprimento de horário nas consultas por parte dos médicos e falta de comunicação entre médico e secretária no gerenciamento de atrasos; imagem corporativa e marca (para novos colaboradores que possuíam outro convênio); e qualidade técnica de alguns médicos (citando casos específicos nas especialidades de otorrinolaringologia e neurologia)". 


\subsubsection{Tratamento de reclamações}

As reclamações mais citadas pelos funcionários, mesmo que com pouca incidência, foram: atendimento no SPAR; demora no agendamento de consultas para determinadas especialidades; e, em alguns casos, qualidade no atendimento médico. Em relação a esse último tipo de reclamação, o entrevistado enfatizou que "muitas vezes as reclamações nem são diretamente sobre o Plano, mas com os médicos credenciados".

Outros tipos de reclamação dificilmente ocorrem, caracterizando-se como casos isolados. Nesse sentido, o número de reclamações vem se mantendo baixo e "tolerável". Havendo reclamações, a empresa contata, habitualmente, a equipe de Pós-Vendas ou o setor de Assistência Social. Segundo o entrevistado, "existiram algumas situações indesejadas, mas fomos ouvidos e os problemas foram resolvidos. Nada ficou sem resposta. Os problemas que aconteceram não são rotineiros. Com a implementação do Pós-Vendas, nota-se que o Plano está valorizando mais os clientes e antecipando-se a algumas falhas nos serviços".

Em pesquisa interna realizada pela empresa no intuito de avaliar a satisfação de seus colaboradores em relação aos benefícios oferecidos, 64,23\% dos entrevistados afirmaram estar "muito satisfeitos" com o Plano de Saúde, e 34,97\% afirmaram estar "satisfeitos".

\subsubsection{Comentários gerais e relação empresa-Plano de Saúde}

Sobre os contatos com a equipe de Pós-Vendas, o entrevistado afirmou estar recebendo visitas periódicas e sempre que precisou de informações ou a resolução de algum problema, fora bem atendido. Quanto ao tempo de retorno às solicitações, na maioria dos casos foi satisfatório. Colocou ainda que "o contato com a equipe de Pós-Vendas é tranqüilo, talvez até em função da pessoa que nos visita, pois já a conhecemos há bastante tempo, e a relação é bem próxima".

Os benefícios percebidos por meio de atividades desenvolvidas pela equipe de Pós-
Vendas foram: agilidade nas informações, viabilizando soluções mais rápidas para os problemas; e centralização na comunicação, argumentando que: "saber com quem falar e solicitar alguma providência abrevia o tempo de retorno".

Questionado sobre sua opinião quanto à equipe de Pós-Vendas ser um investimento a longo prazo, por parte do Plano de Saúde, no relacionamento com sua empresa, o entrevistado afirmou que entende que sim. Salientou que: "sem dúvida, entendo que não é somente um investimento, mas também um diferencial do Plano em relação a outros prestadores de serviço que a empresa tem como parceiros. Acredito que a equipe de PósVendas reforça o relacionamento entre as empresas, bem como a imagem do Plano".

Para o entrevistado, tanto a confiança quanto o compromisso em permanecer com o atual convênio foram consolidados, uma vez que as atividades desenvolvidas pela equipe de Pós-Vendas agregam valor: "na realidade já existia uma confiança muito grande, mas a equipe de PósVendas a fortaleceu, o mesmo se aplicando ao compromisso. Nós sentimos a preocupação do Plano em manter um relacionamento, e o PósVendas veio somar esforços, embora ainda estarmos utilizando-o mais para resolver problemas. Temos a impressão de que o Plano está profissionalizando sua estrutura, cada vez mais, melhorando os processos".

Consoante a isso, o entrevistado afirmou haver forte propensão da empresa em permanecer com o atual convênio, numa visão de futuro: "dentro de um contexto geral, não somente pela atuação do Pós-Vendas, existe uma forte propensão em permanecermos como clientes do Plano de Saúde. Se estivermos bem atendidos e as pessoas satisfeitas, não há por que pensarmos em trocar de parceiro".

\subsection{Cliente B}

\subsubsection{Identificação do cliente e entendimento do convênio}

O entrevistado é um dos proprietários de uma empresa do ramo gráfico, exercendo papel tanto 
de decisor quanto de negociador nos processos de contratação de benefícios para seus colaboradores. A empresa foi fundada em 1990 e enfatiza os segmentos de propaganda e editorial, sendo seu mercado compreendido pela região da Serra Gaúcha e da Grande Porto Alegre.

A empresa possuía, anteriormente, convênio com outro plano de saúde, mas em razão das dificuldades no processo de negociação entre as partes optou pela troca de convênio. O processo de negociação inicial e decisão, bem como de manutenção do provedor de saúde atual, sempre foi marcado por facilidade nas negociações.

$\mathrm{O}$ entrevistado afirmou haver algumas dúvidas quanto aos direitos e coberturas do convênio e demais serviços, até pela complexidade contratual, citando as coberturas relativas a acidentes de trabalho e às mudanças da Nova Regulamentação. Comentou, também, que o nível de atendimento sempre esteve à altura das expectativas, sugerindo que, periodicamente, alguém do Plano de Saúde vá até sua empresa resgatar algumas informações relevantes, bem como dirimir dúvidas de seus colaboradores, tendo em vista os procedimentos de utilização do sistema e a rotatividade de pessoal.

\subsubsection{Aspectos valorizados, pontos fortes e fracos}

Os aspectos que mais valoriza são: rapidez no atendimento, preocupação (atenção) das pessoas em resolver os problemas e qualidade dos serviços. Exemplificando, comentou: "quando estive no hospital há pouco tempo, observei a preocupação em atender, rapidamente, as pessoas que estavam lá, e isso é muito importante. As pessoas que vão procurar os serviços do Plano não vão por acaso, mas porque não estão se sentindo bem". Acrescentou que, além do aspecto relacionado à saúde de seus colaboradores, a rapidez no atendimento não prejudica a produtividade da empresa, argumentando que "o funcionário não pode perder uma manhã inteira para ser atendido".
Analisando o convênio, o entrevistado identificou como pontos fortes: "atendimento de forma geral; facilidade em negociar; ambiente hospitalar, o qual aparenta clima mais saudável; e investimentos em tecnologia (equipamentos)". Em relação ao atendimento, reforçou: "eu até queria ressaltar a simpatia com que as pessoas nos atendem. $\mathrm{O}$ Plano apresenta um ambiente bastante familiar. Há um tempo atrás precisei resolver um problema de um funcionário, procurei o gerente e, prontamente, fui atendido".

Por outro lado, como pontos fracos ressaltou: "número de médicos; qualidade de alguns médicos; identificação visual em relação ao acesso aos diversos setores no Hospital; cobrança de diferença em determinados exames; imagem dos serviços odontológicos (somente na percepção dos novos colaboradores e que não possuíam este convênio); imagem do Plano de Saúde que está, excessivamente e somente, associada ao Hospital; falta de comunicação entre o Plano e o cliente, embora isto esteja significativamente melhor; e cumprimento de horários de consultas por parte dos médicos".

\subsubsection{Tratamento de reclamações}

Em relação às reclamações, os funcionários comentam sobre a cobrança de diferenças nos exames: "essa é a reclamação que se ouve. Quanto a outros tipos de reclamação, praticamente não existem, apenas algumas outras questões a respeito da falta de informações quanto ao uso do Plano". Para o entrevistado, comparativamente, passados alguns anos, "a incidência de reclamações vem diminuindo, significativamente. A qualidade no atendimento vem melhorando bastante". Quando há alguma reclamação, imediatamente a equipe de Pós-Vendas é contatada.

$\mathrm{Na}$ avaliação do entrevistado, quanto à satisfação de seus colaboradores com o convênio, " $80 \%$ a $90 \%$ do pessoal está satisfeito. Se pudéssemos colocar uma avaliação entre 1 a 10, eu diria que se poderia atribuir à satisfação, nota 8 . Isso até seria interessante de se pesquisar internamente; e caso o Plano tenha interesse, a empresa está à disposição". 


\subsubsection{Comentários gerais e relação empresa-Plano de Saúde}

Questionado sobre os contatos com a equipe de Pós-Vendas, o entrevistado comentou que recebera, até o momento, quatro visitas e sempre que precisou de informações ou resolução de algum problema fora bem atendido, colocando ainda que o tempo de retorno às solicitações foi satisfatório: "o contato com a pessoa de PósVendas personalizou o atendimento. Conhecer as pessoas do Plano facilita o atendimento e diminui a distância entre as pessoas e o Plano, criando um vínculo".

Os benefícios percebidos por meio de atividades desenvolvidas pela equipe de Pós-Vendas foram: aproximação da empresa com o Plano, sendo esse ressaltado como o principal benefício; e resgate das informações sobre coberturas, direitos e procedimentos para a melhor utilização dos serviços, aperfeiçoando a comunicação.

Em relação à percepção da equipe de PósVendas como sendo um investimento de longo prazo, por parte do Plano de Saúde, no relacionamento com sua empresa, o entrevistado afirmou que entende que sim, "uma vez que o Pós-Vendas está aproximando as empresas. Como os concorrentes têm interesse, anterior às visitas realizadas pela equipe, recebíamos mais visitas de vendedores dos concorrentes do que do Plano de Saúde. Esse contato é um ponto positivo e entendo que esse tipo de postura reforçará, cada vez mais, o vínculo entre as empresas".

Além disso, o entrevistado afirmou que sua percepção, tanto de confiança, quanto de compromisso em permanecer com o atual convênio, aumentou a partir da aproximação da equipe de Pós-Vendas: "percebe-se um grande interesse do Plano em permanecer com a empresa como cliente, uma coisa que não vinha sendo demonstrada anteriormente, e isso é fundamental. Acredito que há um investimento de longo prazo de ambas as partes, pois um convênio com plano de saúde não deve ser trocado de um mês para outro. A visão que o Plano está nos transmitindo é que o relacionamento é uma continuação de parceria, por muito tempo".
Finalmente, indagado sobre a tendência de sua empresa em permanecer com o atual convênio de Plano de Saúde, a longo prazo, afirmou estar surpreso pela atenção que vem recebendo, uma vez que após nove anos como cliente nunca havia sido visitado, e que tal aproximação e sua valorização como cliente, aliadas à qualidade do atendimento prestado, reforçam sua intenção em manter o convênio.

\subsection{Cliente C}

\subsubsection{Identificação do cliente e entendimento do convênio}

A entrevistada é um dos proprietários de uma empresa do comércio atacadista de bebidas, assumindo a função tanto de decisão quanto de negociação nos processos de contratação de benefícios para seus colaboradores. A empresa foi fundada em 1997 e possui três linhas de produto: refrigerante, cerveja e água mineral. A abrangência territorial de seu mercado é compreendida pelas principais cidades da Serra Gaúcha, e dois de seus principais fornecedores são a AMBEV e a Pepsi-Cola.

A empresa possui o convênio desde sua fundação, ressaltando a proximidade entre as empresas, principalmente pela facilidade em negociar. Entretanto, tendo em vista as modificações na legislação, provenientes da Nova Regulamentação, afirmou haver algumas dúvidas em relação aos direitos, coberturas e taxas de participação.

\subsubsection{Aspectos valorizados, pontos fortes e fracos}

Os aspectos mais valorizados na prestação de serviços do convênio são: facilidade na comunicação e, por decorrência, liberdade em dialogar com as pessoas do Plano; e qualidade no atendimento.

Um aspecto relevante que a entrevistada relatou é que "como a maioria de nossos funcionários vem do interior e em suas cidades não há plano de saúde, a expectativa deles em relação à qualidade dos serviços é baixa, tornando-se fácil satisfazê-los". 
Ao analisar o convênio, a entrevistada identificou como pontos fortes: "proximidade entre as empresas; atendimento de forma geral, enfatizando o atributo cordialidade; e estrutura da Clínica". Em relação ao atendimento, embora satisfeita, citou alguns exemplos de situações que deixaram a desejar, referindo-se à atitude dos atendentes: "como o atendimento depende de pessoas e cada uma tem sua personalidade e forma de atender, as chefias devem acompanhar mais. Existem algumas falhas, como em todo tipo de serviço, ainda mais na área da saúde. Algumas pessoas do atendimento demoram muito".

Também registrou como pontos fracos: "número de médicos nas especialidades de pediatria e ginecologia; qualidade técnica de alguns médicos; falta eventual de leitos para internação no Hospital; variabilidade no atendimento, atribuída às características pessoais e comportamentais de alguns atendentes; e falta de atualização constante de informações".

\subsubsection{Tratamento de reclamações}

As reclamações, praticamente inexistentes, se resumem a dúvidas quanto às taxas de participação. Na avaliação da entrevistada, seus colaboradores estão satisfeitos com o convênio: "se fosse atribuir uma nota, avaliaria a satisfação do pessoal pela nota 8 ".

\subsubsection{Comentários gerais e relação empresa-Plano de Saúde}

Questionada a respeito dos contatos com a equipe de Pós-Vendas, a entrevistada disse ter recebido três visitas e sempre que precisou dirimir alguma dúvida, enfatizando as taxas de participação, foi prontamente atendida, ressaltando, ainda, que não apenas pela equipe de Pós-Vendas, mas também pelo setor de Assistência Social. Como benefícios percebidos por meio das atividades desenvolvidas pela equipe de Pós-Vendas, foram identificados: aproximação da empresa com o Plano e, principalmente, disponibilidade de um canal de contato, no qual o cliente possa ser ouvido. Segundo entrevistada: "a equipe de Pós-Vendas possibilita que o cliente conheça melhor seus direitos, como proceder em alguns casos específicos e com quem deve tratar, proporcionando contatos mais direcionados".

Ao ser indagada quanto à sua percepção sobre a equipe de Pós-Vendas ser um investimento a longo prazo, por parte do Plano de Saúde, no relacionamento com sua empresa, a entrevistada afirmou entender que sim, colocando: "como toda empresa depende muito de seus clientes e todos gostam de ser ouvidos e valorizados, a equipe de Pós-Vendas torna-se um vínculo entre o Plano e a empresa. A atenção e o retorno às solicitações provenientes da atuação do PósVendas são essenciais. Saber a quem recorrer, tendo a segurança de que algum problema que ocorra será resolvido faz com que nossa tolerância a alguns erros aumente".

A entrevistada comentou que sua percepção, tanto de confiança quanto de compromisso em permanecer com o atual convênio, não mudou, por considerar que ambas apresentam alto nível, tendo em vista sua proximidade com o Plano de Saúde, e reforçando que "se sente em casa". Contudo, salientou que a equipe de Pós-Vendas, embora não tenha alterado sua percepção de confiança e compromisso, certamente fortaleceu o relacionamento entre as empresas.

Concluindo, ao ser questionada sobre a tendência de sua empresa em permanecer com o atual convênio de Plano de Saúde, a longo prazo, afirmou haver forte tendência em manter o convênio.

\section{Análise dos resultados}

Neste item, é apresentada a análise dos dados provenientes das entrevistas com clientes, as quais foram sumarizadas e descritas no item anterior. Foi estabelecido como critério de identificação dos dados para análise, sob a ótica do pesquisador, o valor das observações e sua relevância para os objetivos propostos pelo estudo. Inicialmente, notase que o principal aspecto que as empresas e seus funcionários avaliam quanto à prestação de serviços do convênio é a qualidade do atendimento. Outros aspectos, como rapidez, atenção e preocupação das pessoas em resolver os problemas, também surgem nos relatos, conforme o Quadro 2. 
Em relação à análise da estrutura do convênio, de acordo com os Quadros 3 e 4, observa-se como principais pontos fortes: atendimento de forma geral, facilidade em negociar e proximidade entre as empresas. Como pontos fracos, os mais citados foram: número de médicos, com algumas especialidades específicas sendo identificadas (como é o caso da gastroenterologia e otorrinolaringologia, para o cliente A e pediatria e ginecologia, para o cliente $\mathrm{C}$ ); qualidade do atendimento de alguns médicos (identificados nas especialidades de neurologia e otorrinolaringologia, pelo cliente A); cumprimento de horário nas consultas por parte dos médicos; falta de comunicação e atualização de informações; e imagem corporativa e marca (somente para novos colaboradores que possuíam outro convênio).

Em relação aos tipos de reclamação mais freqüentes que recebem de seus funcionários e, até mesmo, por suas experiências de uso, conforme Quadro 5, os entrevistados indicaram a cobrança de diferença em exames e dúvidas quanto ao valor das taxas de participação como as mais freqüentes, sendo seguidas por reclamações do atendimento no SPAR, junto ao Hospital; qualidade no atendimento de alguns médicos; e demora no agendamento de consultas (em algumas especialidades).

Cabe ressaltar que os entrevistados afirmaram haver poucas reclamações ou mesmo estarem diminuindo. Para o cliente A, as reclamações têm "pouca incidência"; para o cliente B, "a incidência de reclamações vem diminuindo significativamente"; e para o cliente C, "praticamente não existem". Vale observar que os Quadros 2, 3, 4 e 5 revelam diferenças entre as percepções dos clientes entrevistados. Os principais aspectos avaliados, a percepção de pontos fortes e fracos e as próprias reclamações referentes ao serviço prestado são diferentes conforme o cliente analisado, apesar de o serviço prestado ser essencialmente o mesmo. Esses dados indicam que o serviço ideal, na área em estudo, é fortemente dependente do cliente que o recebe. O Plano de Saúde é utilizado por empresas pequenas, médias e grandes, de todos os setores, caracterizando um perfil de clientes que apresenta grande heterogeneidade. As necessidades dessas empresas são muito diferentes, assim como o nível de serviço exigido.

Quanto ao nível de satisfação dos clientes em relação ao Plano de Saúde, pôde-se observar que estes estão satisfeitos, conforme apresentado no Quadro 6. O cliente A, inclusive, disponibilizou uma pesquisa interna realizada pela empresa, na qual $64,23 \%$ dos estrevistados afirmaram estar "muito satisfeitos" com o convênio de saúde e 34,97\%, "satisfeitos". Já na percepção dos clientes B e C, se fossem estimar uma nota para avaliar o nível de satisfação de seus funcionários, ambos atribuiriam o conceito 8. A disponibilização da equipe de Pós-Vendas aos clientes trouxe, na percepção dos entrevistados, dois benefícios principais, os quais são observados no Quadro 7.

O primeiro está relacionado à melhoria no nível de comunicação e informações, que passaram a ser acessadas pelos clientes de forma mais ágil, ressaltando que a centralização de algumas informações, com a equipe de Pós-Vendas, facilitou o encaminhamento de soluções mais rápidas para os problemas.

\section{Quadro 2 - Principais aspectos avaliados na prestação de serviços do convênio.}

\begin{tabular}{lccc}
\hline \multicolumn{1}{c}{ Aspectos avaliados } & Cliente A & Cliente B & Cliente C \\
\hline Qualidade do atendimento/serviços & $\mathrm{X}$ & $\mathrm{X}$ & $\mathrm{X}$ \\
Rapidez & $\mathrm{X}$ & $\mathrm{X}$ & \\
Atenção/preocupação das pessoas em resolver os problemas & $\mathrm{X}$ & $\mathrm{X}$ & \\
Cumprimento do contrato & $\mathrm{x}$ & & \\
Retorno às solicitações & $\mathrm{x}$ & & \\
Comunicação facilitada & & & $\mathrm{x}$ \\
\hline
\end{tabular}




\section{Quadro 3 - Pontos fortes da estrutura do convênio na percepção dos clientes.}

\begin{tabular}{lccc}
\hline \multicolumn{1}{c}{ Pontos fortes } & Cliente A & Cliente B & Cliente C \\
\hline Atendimento de forma geral & $\mathrm{X}$ & $\mathrm{X}$ & $\mathrm{X}$ \\
Facilidade em negociar/proximidade entre as empresas & $\mathrm{X}$ & $\mathrm{X}$ & $\mathrm{X}$ \\
Relação custo-benefício & $\mathrm{X}$ & & \\
Estrutura da clínica & & & $\mathrm{X}$ \\
Limpeza/nível de informações no Hospital/ambiente do Hospital & $\mathrm{X}$ & $\mathrm{X}$ & \\
Ambulatório & $\mathrm{X}$ & \\
Farmácia (atendimento e horários) & $\mathrm{X}$ & \\
Investimentos em tecnologia (equipamentos) & & $\mathrm{X}$ & \\
Imagem corporativa (para quem já possui convênio com o Plano) & $\mathrm{X}$ & & \\
\hline
\end{tabular}

\section{Quadro 4 - Pontos fracos da estrutura do convênio na percepção dos clientes.}

\begin{tabular}{|c|c|c|c|}
\hline Pontos fracos & Cliente A & Cliente B & Cliente $\mathbf{C}$ \\
\hline Número de médicos & $\mathrm{x}$ & $\mathrm{x}$ & $\mathrm{x}$ \\
\hline Qualidade de alguns médicos & $\mathrm{x}$ & $x$ & $\mathrm{x}$ \\
\hline $\begin{array}{l}\text { Atendimento do SPAR (relação entre tempo de espera para } \\
\text { diagnóstico e encaminhamento do cliente) }\end{array}$ & $\mathrm{x}$ & & \\
\hline Variabilidade na qualidade do atendimento por idiossincrasias & & & $\mathrm{x}$ \\
\hline Demora no agendamento de consultas (em algumas especialidades) & $\mathrm{x}$ & & \\
\hline Cumprimento de horário nas consultas por parte dos médicos & $\mathrm{x}$ & $x$ & \\
\hline Falta de comunicação e atualização de informações & & $\mathrm{x}$ & $\mathrm{x}$ \\
\hline $\begin{array}{l}\text { Falta de comunicação entre médico e secretária no gerenciamento de } \\
\text { atrasos }\end{array}$ & $\mathrm{x}$ & & \\
\hline $\begin{array}{l}\text { Identificação visual em relação ao acesso aos diversos setores do } \\
\text { Hospital }\end{array}$ & & $x$ & \\
\hline Falta eventual de leitos para internação no Hospital & & & $\mathrm{x}$ \\
\hline Cobrança de diferença em determinados exames & & $\mathrm{x}$ & \\
\hline $\begin{array}{l}\text { Imagem corporativa e marca (para novos colaboradores que } \\
\text { possuíam outro convênio) }\end{array}$ & $x$ & $x$ & \\
\hline $\begin{array}{l}\text { Imagem dos serviços odontológicos (para novos colaboradores que } \\
\text { possuíam outro convênio) }\end{array}$ & & $x$ & \\
\hline
\end{tabular}

\section{Quadro 5 - Reclamações mais freqüentes.}

\begin{tabular}{lccc}
\hline \multicolumn{1}{c}{ Tipo de reclamação } & Cliente A & Cliente B & Cliente C \\
\hline Atendimento no SPAR & $\mathrm{X}$ & & \\
Qualidade ao atendimento de alguns médicos & $\mathrm{X}$ & & \\
$\begin{array}{l}\text { Demora no agendamento de consultas (em algumas especialidades) } \\
\text { Cobrança de diferença em determinados exames/dúvidas quanto às }\end{array}$ & $\mathrm{X}$ & & \\
taxas de participação & $\mathrm{x}$ & $\mathrm{X}$ \\
\hline
\end{tabular}


Quadro 6 - Nível de satisfação estimado.

\begin{tabular}{clc}
\hline Clientes & \multicolumn{1}{c}{ Opinião dos entrevistados quanto ao nível de satisfação estimado } & Nota estimada \\
\hline A & $64,23 \%$ "muito satisfeitos" e $34,97 \%$ "satisfeitos" (dados de pesquisa interna) & Não estimada \\
B & "80\% a 90\% do pessoal está satisfeito" & 8 \\
C & Os “colaboradores estão satisfeitos com o convênio" & 8 \\
\hline
\end{tabular}

\section{Quadro 7 - Benefícios atribuídos à disponibilização da equipe de Pós-Vendas.}

\begin{tabular}{lccc}
\hline \multicolumn{1}{c}{ Benefícios } & Cliente A & Cliente B & Cliente C \\
\hline $\begin{array}{l}\text { Melhoria no nível de comunicação e informações (resgate, } \\
\text { agilidade e centralização das informações/soluções mais rápidas } \\
\text { para os problemas) }\end{array}$ & $\mathrm{X}$ & $\mathrm{X}$ & $\mathrm{X}$ \\
\begin{tabular}{l} 
Aproximação da empresa com o Plano \\
\hline
\end{tabular} & $\mathrm{x}$ & $\mathrm{X}$ \\
\hline
\end{tabular}

O segundo está direcionado à maior aproximação das empresas com o Plano de Saúde. Alguns outros questionamentos foram resgatados, de acordo com o Quadro 8. Quanto à percepção da equipe de Pós-Vendas como um investimento a longo prazo do Plano de Saúde no relacionamento com as empresas, todos os entrevistados afirmaram perceber, ressaltando, direta ou indiretamente, sentirem-se valorizados.

Em relação à atuação da equipe de Pós-Vendas e às variáveis confiança e compromisso o cliente A externou que tanto o compromisso quanto a confiança foram consolidados; e para o cliente $\mathrm{B}$, ambos aumentaram. Para o cliente $\mathrm{C}$, nem a confiança nem o compromisso aumentaram em razão da implementação da equipe de Pós-Vendas, pois, em sua avaliação, ambas as variáveis permanecem em alto grau. Finalmente, em relação à propensão em permanecerem engajados com o atual convênio, sob uma visão a longo prazo, os entrevistados definiram seu grau de propensão como fortemente propensos ou tendo sua intenção reforçada a partir das atividades desenvolvidas pela equipe de Pós-Vendas.

\section{Quadro 8 - Equipe de Pós-Vendas como investimento a longo prazo, níveis de confiança e compromisso e propensão em permanecer com o convênio.}

\begin{tabular}{lccc}
\hline \multicolumn{1}{c}{ Questionamentos } & Cliente A & Cliente B & Cliente C \\
\hline $\begin{array}{l}\text { Você percebe a equipe de Pós-Vendas como um investimento com } \\
\text { visão a longo prazo do Plano de Saúde no relacionamento com sua } \\
\text { empresa ou não? }\end{array}$ & Sim & Sim & Sim \\
$\begin{array}{l}\text { A atuação da equipe de Pós-Vendas modificou sua percepção em } \\
\text { termos de confiança (...)? }\end{array}$ & Consolidou & Aumentou & $\begin{array}{c}\text { Permaneceu } \\
\text { alta }\end{array}$ \\
$\begin{array}{l}\text { (...) e compromisso em permanecer com este convênio? } \\
\begin{array}{l}\text { Você valoriza esse tipo de iniciativa (as ações desenvolvidas pela } \\
\text { equipe de Pós-Vendas)? }\end{array}\end{array}$ & Consolidou & Aumentou & $\begin{array}{c}\text { Permaneceu } \\
\text { alto }\end{array}$ \\
$\begin{array}{l}\text { A partir da atuação da equipe de Pós-Vendas, como você avaliaria } \\
\text { sua propensão em permanecer com este convênio a longo prazo? }\end{array}$ & $\begin{array}{c}\text { Forte } \\
\text { propensão }\end{array}$ & $\begin{array}{c}\text { Intenção } \\
\text { reforçada }\end{array}$ & $\begin{array}{c}\text { Forte } \\
\text { tendência }\end{array}$ \\
\hline
\end{tabular}




\section{Discussão e interpretação dos dados}

Tomando por base a análise dos dados, pôdese observar algumas relações que explicam os resultados provenientes da implementação do Departamento de Pós-Vendas para a empresa estudada sob o prisma dos objetivos propostos para a esta pesquisa.

Observa-se que, quanto à influência da prática do Departamento de Pós-Vendas sobre a retenção de clientes, ou melhor, sobre o desejo futuro dos clientes permanecerem engajados ao atual provedor de saúde, todos os entrevistados afirmaram haver forte tendência em manuterem-se clientes. Embora as ações advindas da equipe de Pós-Vendas não sejam exclusivamente as responsáveis pela retenção de clientes, estes afirmaram que tais iniciativas são bastante valorizadas.

Uma vez que os clientes avaliaram como principal aspecto na prestação de serviços do convênio a qualidade do atendimento, o mesmo atributo apontado como o principal ponto forte do Plano de Saúde, juntamente à facilidade de negociação e proximidade entre as empresas, notam-se que as atividades desenvolvidas pela equipe de PósVendas consolidam a proximidade entre as organizações, relembrando que seu objetivo central é estabelecer e fortalecer os relacionamentos existentes, sem falar em sua conduta propulsora de mudanças em processos que geravam e/ou geram reclamações por parte dos clientes.

Nesse sentido, foram detectados alguns pontos fracos na estrutura do convênio, os quais merecem atenção especial, como o número e a qualidade de alguns médicos. Mesmo com esses pontos fracos, salienta-se que a qualidade do atendimento, de forma geral, é elogiada. Uma possível explicação pode ser o fato de os clientes tolerarem algumas deficiências diretamente relacionadas ao corpo clínico do convênio, talvez pelo entendimento da dificuldade de gerir tais profissionais ou de ampliar o quadro existente.

Embora não haja dados anteriores à implementação do Departamento de Pós-Vendas para comparar e melhor interpretar os dados, verifica- se que o nível de satisfação dos clientes com o convênio é alto. Logicamente, não se deve atribuir tais níveis de satisfação somente à implementação do Departamento, contudo, este é um indicador que pode justificar, mesmo que indiretamente, uma possível influência das ações de Pós-Vendas na retenção de clientes.

Quanto à sua validação, pode-se dizer que a equipe de Pós-Vendas está conseguindo transmitir aos clientes dois aspectos que reforçam o relacionamento clientes-Plano de Saúde, os quais são percebidos como benefícios atribuídos à disponibilização da equipe: melhoria no nível de comunicação e informações entre as partes e aproximação das empresas com o Plano de Saúde.

Como todos os entrevistados afirmaram valorizar as ações desenvolvidas pela equipe de PósVendas, bem como entenderam-na como um investimento com visão a longo prazo do Plano de Saúde no relacionamento com sua empresa, infere-se que a implementação do Departamento de Pós-Vendas pode representar um papel fundamental para a retenção futura dos clientes do Plano de Saúde, estreitando os elos e, conseqüentemente, os relacionamentos a longo prazo.

Outras variáveis que indicam a validade da equipe de Pós-Vendas são a confiança e o compromisso dos clientes em relação ao convênio. Embora um dos entrevistados tenha afirmado que em ambas as variáveis as ações da equipe de PósVendas não alteraram seu nível de avaliação, fez questão de registrar que a confiança e o compromisso permanecem altos, consoante à sua intenção em permanecer com o convênio.

Por sua vez, os dois outros entrevistados comentaram que a atuação da equipe de PósVendas consolidou ou aumentou os níveis de confiança e compromisso com o atual convênio. Se entendidas como variáveis mediadoras do relacionamento, pode-se dizer que a prática da equipe de Pós-Vendas influencia positivamente nos níveis de confiança e compromisso dos clientes em relação ao Plano de Saúde e que, por decorrência, fortalece os relacionamentos existentes e uma provável expectativa quanto à retenção de clientes a longo prazo. 


\section{Comparação dos resultados com a literatura}

$\mathrm{O}$ marketing de relacionamento emergiu na literatura sugerindo o estabelecimento de relacionamentos próximos e de longo prazo com os clientes, possibilitando às organizações uma corrente futura de lucratividade (Berry, 1993). Contudo, para que um relacionamento exista, ele deve ser reconhecido por ambas as partes - conceito de mutualidade - e se desenvolver na base de contatos significativos - conceito de status especial (Rowe \& Barnes, 1998), exatamente ao que se propõe a equipe de Pós-Vendas em estudo.

Cabe ressaltar que, para a prática de PósVendas desenvolvida pela empresa, a retenção de clientes não é um fim em si mesma, mas o resultado desejado ao final da consolidação de relacionamentos com os clientes. Muitas empresas que focam somente a retenção de clientes, uma das perspectivas do marketing de relacionamento, gastam desnecessariamente recursos tentando ser tudo, para todos os clientes. Na verdade, deveriam considerar que alguns clientes exigem mais recursos da organização do que dos benefícios que acabam lhes gerando (Rowe \& Barnes, 1998).

Por isso, as atividades de Pós-Vendas devem focar, primeiramente, os relacionamentos, tendo por resultado desejado, então, a satisfação e a retenção dos clientes. Conforme proposto por Rowe \& Barnes (1998), um relacionamento construído à luz dos conceitos de mutualidade e status especial tem potencial para gerar vantagem competitiva sustentável para a empresa.

Embora a ligação entre satisfação e retenção de clientes seja controversa, além de haver poucas evidências empíricas a respeito da relação entre satisfação e longevidade do relacionamento, tal relação não pode ser negada (Bolton, 1998). Anderson (1994) descobriu que a correlação entre satisfação e intenções de compra é mais forte entre empresas quando o envolvimento ou a experiência são altos. Como os serviços relacionados à saúde são propensos ao alto envolvimento, principalmente o emocional, e à troca de experiências entre clientes e provedor de saúde, a função da equipe de Pós-Vendas é consolidar, positivamente, tanto o envolvimento quanto a experiência entre as partes. Para Parvatiyar \& Sheth (2000), a comunicação com clientes ajuda no desenvolvimento do relacionamento, fomenta a confiança e fornece informações e conhecimentos necessários aos parceiros para o empreendimento de atividades cooperativas e colaborativas. Assim, ressalta-se a importância de os clientes terem percebido como um dos benefícios da disponibilização da equipe de Pós-Vendas a melhoria no nível de comunicação e informações.

Duas proposições confirmadas por De Wulf et al. (2001) chamam a atenção. A primeira é que um nível percebido mais alto de comunicação interpessoal leva a um nível percebido mais alto de investimento no relacionamento. A segunda é que um nível percebido mais alto de investimento no relacionamento leva a um nível mais alto de qualidade do relacionamento. Como todos os entrevistados entenderam a prática da equipe de PósVendas como um investimento a longo prazo, por parte do Plano de Saúde, pode-se relacionar essa percepção dos clientes à qualidade mais alta do relacionamento existente entre as partes.

De acordo com Morgan \& Hunt (1994), o compromisso e a confiança são variáveis mediadoraschave do relacionamento, associadas à cooperação, a qual é exigida para que os relacionamentos sejam bem-sucedidos. $\mathrm{O}$ compromisso representa o mais alto estágio de elos relacionais entre as partes (Dwyer et al., 1987), enquanto a confiança é vista como um determinante da qualidade do relacionamento (Moorman et al., 1992). Assim sendo, nota-se que, pela percepção dos entrevistados, a empresa pode estar baseando seus relacionamentos sob a ótica dos elos relacionais, melhorando a qualidade dos relacionamentos existentes e possibilitando, mesmo que indiretamente, a melhoria do nível de retenção de clientes.

\section{Conclusões e desenvolvimentos futuros}

A fim de ampliar a discussão sobre a interrelação existente entre estabelecimento, manutenção e incremento dos relacionamentos entre fornecedor- 
cliente e seu possível impacto sobre a retenção de clientes, utilizou-se a pesquisa qualitativa como forma de investigação em um caso de implementação de um Departamento de Pós-Vendas de uma empresa de medicina de grupo.

Em razão de o estudo ser direcionado a um setor específico de atividades, desconsiderando outros contextos, bem como algumas limitações da metodologia empregada, como, por exemplo, a representatividade da amostra selecionada, há restrições de generalização quanto às descobertas, o que, por sua vez, poderá estimular pesquisas complementares.

Contudo, no ambiente estudado e à luz dos objetivos propostos, conclui-se que as ações desenvolvidas pela equipe de Pós-Vendas podem exercer influência significativa em relação à consolidação dos relacionamentos com os clientes e à retenção dos mesmos. Como os clientes entendem que o Departamento de Pós-Vendas é um investimento com visão a longo prazo do Plano de Saúde no relacionamento, tal investimento pode reforçar a percepção de confiança e a intenção de compro- metimento dos clientes na manutenção do atual convênio. Como ampliação desta pesquisa, propõese que alguns outros elementos possam vir a ser estudados ou melhor discutidos, como é o caso de alguns antecedentes da confiança e do compromisso, propostos por Hunt et al. (2002), que são: custos de término do relacionamento, valores partilhados, eficácia da comunicação e comportamento oportunista, sendo que este último pode ser tratado como oportunismo ativo ou passivo (Wathne \& Heide, 2000); e qual o papel da equipe de Pós-Vendas em relação a cada uma dessas variáveis e sua possível influência no desempenho da empresa. Outros desenvolvimentos futuros poderiam abordar, também, aspectos como: efeitos da assimetria de poder entre parceiros (Morgan \& Hunt, 1994); impacto de atos destrutivos sobre a longevidade do relacionamento (Hibbard et al., 2001) e como a equipe de Pós-Vendas poderia minimizá-los; e dependência do cliente em relação ao fornecedor e nível de comparação de fornecedores alternativos (Wilson \& Vlosky, 1997).

\section{Referências Bibliográficas}

ANDERSON, E. W. Cross-category variation in customer satisfaction and retention. Marketing Letters, v. 5, p. 19-30, 1994.

ASBRAND, D. Is your automated customer service killing you? Datamation, v. 43, n. 5, p. 62-67, 1997.

BERRY, L. L. Relationship marketing. In: BERRY, L. L.; SHOSTACK, G. L.; OPAH, G. (Ed.). Emerging perspectives in service marketing. Chicago: AMA, 1993. p. 25-28.

BERRY, L. L. Relationship marketing of services perspectives from 1983 and 2000. Journal of Relationship Marketing, v. 1, n. 1, p. 59-77, 2002.

BOLTON, R. N. A dynamic model of the duration of the customer's relationship with a continuous provider: the role of satisfaction. Marketing Science, v. 17, n. 1, p. 45-65, 1998.

CAMPOS, A. B. F.; RAMOS, R. E. B. Fatores que afetam a satisfação do cliente: estudo de caso com compradores de automóveis. ENEGEP, 22., Curitiba, 2002. Anais... Curitiba: ABEPRO, 2002. Em CD-ROM.
DAHMER, L. V.; ESTRADA, R. J. A relação existente entre o grau de satisfação dos clientes e dos consumidores de uma indústria alimentícia do Rio Grande do Sul. ENEGEP, 22., Curitiba, 2002. Anais... Curitiba: ABEPRO, 2002. Em CD-ROM.

De WULF, K.; ODEKERKEN-SCHRÖDER, G.; IACOBUCCI, D. Investments in consumer relationships: a cross-country and cross-industry exploration. Journal of Marketing, v. 65, p. 3350, 2001.

DWYER, F. R.; SCHURR, P. H.; OH, S. Developing buyer-seller relationships. Journal of Marketing, v. 51, p. 11-27, 1987.

GLASENAPP, S.; SOUZA, P. O.; BACIN, E. T.; RIGHI, C. A. Identificação do grau de utilização e satisfação dos clientes dos serviços da sala de autoatendimento do banco X. ENEGEP, 22, Curitiba, 2002. Anais... Curitiba: ABEPRO, 2002. Em CD-ROM.

GRÖNROOS, C. Relationship marketing: the Nordic school perspective. In: Handbook of relationship marketing. Thousand Oaks, Sage, p. 95-117, 2000. 
GUMMESSON, E. Implementation requires a relationship marketing paradigm. Academy of Marketing Science, v. 26, n. 5, p. 242-249, 1998.

HELLEBUSCH, S. Don't read research by the numbers. Marketing News, v. 34, n. 19, 2000.

HERMOSILLA, J. L.; RODRIGUES, G. A.; COLENCI, A. T. Diferenças nas percepções de qualidade em serviços: um estudo de caso. ENEGEP, 22., Curitiba, 2002. Anais... Curitiba: ABEPRO, 2002. Em CD-ROM.

HIBBARD, J. D.; KUMAR, N.; STERN, W. Examining the impact of destructive acts in marketing channel relationships. Journal of Marketing Research, v. 38, p. 45-61, 2001.

HUNT, S. D.; LAMBE, C. J.; WITTMANN, C. M. A theory and model of business alliance success. Journal of Relationship Marketing, v. 1, n. 1, p. 17-35, 2002.

HYDE, K. F. Recognizing deductive processes in qualitative research. Qualitative Market Research, v. 3, n. 2, p. 82-89, 2000.

KNOWLES, A. Get the complete picture. Datamation, v. 43, n. 10, p. 74-79, 1997.

MILAN, G. S. A estratégia de retenção de clientes e o estabelecimento de relacionamentos como vantagem competitiva: um plano de ações aplicado a uma empresa de medicina de grupo. 2002. Dissertação (Mestrado) - UFRGS/PPGEP, Porto Alegre.

MOORMAN, C.; ZALTMAN, G.; DESHPANDE, $R$. Relationships between providers and users of market research: the dynamics of trust within and between organizations. Journal of Marketing, v. 29, p. 314-328, 1992.

MORGAN, R. M.; HUNT, S. D. The commitmenttrust theory of relationship marketing. Journal of Marketing, v. 58, n. 3, p. 20-38, 1994.

NASCIMENTO, V. M.; MARTINS, H. S.; LEDOUX, P. P. O uso de ferramentas da qualidade na melhoria da satisfação do cliente: estudo de caso em um instituto de educação. ENEGEP, 22., Curitiba, 2002. Anais... Curitiba: ABEPRO, 2002. Em CD-ROM.

PARVATIYAR, A.; SHETH, J. N. The domain and conceptual foundations. Handbook of Relationship Marketing. Thousand Oaks, Sage, p. 3-38, 2000.

PINHEIRO, M. I.; GODOY, L. P. Qualidade em serviços: uma análise da satisfação dos usuários em bibliotecas universitárias. ENEGEP, 22., Curitiba, 2002. Anais... Curitiba: ABEPRO, 2002. Em CD-ROM.
PORTER, M. E. Vantagem competitiva: criando e sustentando um desempenho superior. Rio de Janeiro: Campus, 1989.

REICHHELD, F. F. Loyalty-based management. Harvard Business Review, n. 71, p. 64-73, 1993.

REICHHELD, F. F.; MARKEY Jr., R. G.; HOPTON, C. The loyalty effect - the relationship between loyalty and profits. European Business Journal, v. 12, n. 3, p. 134-139, 2000.

REICHHELD, F. F.; SASSER Jr., E. W. Zero defections: quality comes to service. Harvard Business Review, n. 68, p. 105-111, 1990.

ROWE, G. W.; BARNES, J. G. Relationship marketing and sustained competitive advantage. Journal of Market Focused Management, v. 2, p. 281-297, 1998.

RUST, R. T.; ZAHORIK, A. J. Customer satisfaction, customer retention and market share. Journal of Retailing, v. 69, n. 2, p. 193-215, 1993.

RUST, R. T.; ZEITHAML, V.; LEMON, K. N. $O$ valor do cliente. Porto Alegre: Bookman, 2001.

SALOMI, G. G.; MIGUEL, P. A. C. Aplicação de modelos de avaliação da qualidade em serviços para mensuração da satisfação de clientes internos em uma empresa do setor industrial. ENEGEP, 22., Curitiba, 2002. Anais... Curitiba: ABEPRO, 2002. Em CD-ROM.

SKINNER, D.; TAGG, C.; HOLLOWAY, J. Managers and research: the pros and cons of qualitative approaches. Management Learning, v. 31, n. 2, p. 163-179, 2000.

SOUZA, A. C.; SILVA, S. C. Estudo comparativo do nível de satisfação e de resolutibilidade médica por usuários de diferentes sedes de uma clínica. ENEGEP, 22., Curitiba, 2002. Anais... Curitiba: ABEPRO, 2002. Em CD-ROM.

SOUZA, A. M.; RAMOS, P. C. F.; RAMOS, R. E. B. Um estudo da medição da satisfação do cliente aplicado no setor turístico em Natal/RN. ENEGEP, 22., Curitiba, 2002. Anais... Curitiba: ABEPRO, 2002. Em CD-ROM.

SOUZA, A. S. Percepções e respostas de consumidores frente ao potencial de insatisfação presente nas oficinas de automóveis. ENEGEP, 22., Curitiba, 2002. Anais... Curitiba: ABEPRO, 2002. Em CD-ROM.

VAVRA, T. G. Selling after the sale; the advantages of aftermarketing. Supervision, Burlington, v. 55, n. 10, 1994. 
VAVRA, T. G.; PRUDEN, D. R. Using aftermarketing to maintain a customer base. Discount Merchandiser, Bristol, v. 35, n. 5, 1995.

WATHNE, K. H.; HEIDE, J. B. Opportunism in interfirm relationship: forms, outcomes and solution. Journal of Marketing, v. 64, n. 4, p. 36-51, 2000.
WILSON, E. J.; VLOSKY, R. P. Partnering relationships activities: building theory from case study research. Journal of Business Research, v. 39, p. 59-70, 1997.

YIN, R. K. Case study research: design and method. 2. ed. Sage Publications: Thousand Oaks, CA, 1994.

\section{ANEXO A - Roteiro para as entrevistas (Sessões 1 e 2)}

\begin{tabular}{|c|c|c|}
\hline Inicial & $\begin{array}{l}\text { 1. Você poderia relatar desde quando sua } \\
\text { empresa possui este convênio e como foi o } \\
\text { processo de negociação? }\end{array}$ & $\begin{array}{l}\text { 1. Recapitulando, em nosso último encontro, você } \\
\text { disse que os principais pontos fortes e fracos do } \\
\text { convênio são os seguintes: (...) Você acrescentaria ou } \\
\text { excluiria algum? } \\
\text { 2. Quanto à percepção das pessoas em relação à } \\
\text { satisfação, você colocou que elas estão (...) Você } \\
\text { confirma essa percepção ou a alteraria? }\end{array}$ \\
\hline \multirow{3}{*}{ De transição } & \multirow{3}{*}{$\begin{array}{l}\text { 2. Você e seus funcionários têm dúvidas } \\
\text { quanto às suas coberturas e direitos, e sobre } \\
\text { algum procedimento em relação ao seu } \\
\text { convênio? }\end{array}$} & $\begin{array}{l}\text { 3. Você já precisou de ajuda do pessoal do convênio } \\
\text { para resolver algum problema operacional? }\end{array}$ \\
\hline & & $\begin{array}{l}\text { 4. Se precisou, poderia relatar a situação e a forma } \\
\text { como fora tratado? }\end{array}$ \\
\hline & & $\begin{array}{l}\text { 5. A solução ou o encaminhamento preencheu sua } \\
\text { expectativa quanto ao tempo de retorno e seu } \\
\text { resultado? }\end{array}$ \\
\hline \multirow{9}{*}{ Centrais } & \multirow{3}{*}{$\begin{array}{l}\text { 3. Você poderia relatar quais são os } \\
\text { principais aspectos que a empresa e seus } \\
\text { funcionários avaliam na prestação de } \\
\text { serviços do convênio? }\end{array}$} & 6. Você já recebeu visita(s) da equipe de Pós-Vendas? \\
\hline & & $\begin{array}{l}\text { 7. Se recebeu, poderia relatar como foi essa(s) } \\
\text { experiência(s)? }\end{array}$ \\
\hline & & 8. Se você fez alguma solicitação, poderia relatar como \\
\hline & $\begin{array}{l}\text { 4. Quais são os pontos fortes e fracos da } \\
\text { estrutura do convênio? }\end{array}$ & lhe deram retorno? \\
\hline & \multirow{2}{*}{$\begin{array}{l}\text { 5. Que tipo de reclamações você recebe de } \\
\text { seus funcionários em relação ao convênio? } \\
\text { 6. Se houver reclamações, elas vêm } \\
\text { diminuindo ou aumentado em quantidade? }\end{array}$} & $\begin{array}{l}\text { 9. Algum ponto fraco na estrutura do Plano de Saúde } \\
\text { foi minimizado pela atuação da equipe de Pós-Vendas? }\end{array}$ \\
\hline & & $\begin{array}{l}\text { 10. Quais os benefícios que você percebe na } \\
\text { disponibilização da equipe de Pós-Vendas para sua } \\
\text { empresa? }\end{array}$ \\
\hline & $\begin{array}{l}\text { 7. Quando há reclamação, vocês costumam } \\
\text { relatá-la ao Plano de Saúde? }\end{array}$ & $\begin{array}{l}\text { 11. Você percebe a equipe de Pós-Vendas como um } \\
\text { investimento com visão a longo prazo do Plano de }\end{array}$ \\
\hline & $\begin{array}{l}\text { 8. Havendo histórico de reclamação relatada, } \\
\text { para quem relataram e que tipo de tratamento }\end{array}$ & $\begin{array}{l}\text { Saúde no relacionamento com sua empresa ou não? } \\
\text { Por favor, justifique. }\end{array}$ \\
\hline & tiveram? & $\begin{array}{l}\text { 12. A atuação da equipe de Pós-Vendas modificou sua } \\
\text { percepção em termos de confiança no Plano de Saúde e } \\
\text { compromisso em permanecer com este convênio? Por } \\
\text { favor, justifique. }\end{array}$ \\
\hline \multirow[t]{3}{*}{ Resumo } & \multirow[t]{3}{*}{$\begin{array}{l}\text { 9. Resumindo, como você avalia a percepção } \\
\text { do pessoal em relação à satisfação com o } \\
\text { convênio? }\end{array}$} & $\begin{array}{l}\text { 13. Resumindo, você entende que as atividades } \\
\text { desenvolvidas pela equipe de Pós-Vendas são um } \\
\text { investimento do Plano de Saúde em um } \\
\text { relacionamento de longo prazo com sua empresa? }\end{array}$ \\
\hline & & 14. Você valoriza esse tipo de iniciativa? \\
\hline & & $\begin{array}{l}\text { 15. A partir da atuação da equipe de Pós-Vendas, como } \\
\text { você avaliaria sua propensão em permanecer com este } \\
\text { convênio a longo prazo? }\end{array}$ \\
\hline Final & $\begin{array}{l}\text { 10. Finalizando, como você encara a relação } \\
\text { da empresa com o Plano de Saúde? Por } \\
\text { favor, comente: }\end{array}$ & $\begin{array}{l}\text { 16. A equipe de Pós-Vendas aumentou sua confiança } \\
\text { no Plano de Saúde e seu compromisso em permanecer } \\
\text { com este convênio a longo prazo? }\end{array}$ \\
\hline
\end{tabular}




\title{
THE INFLUENCE OF THE AFTER-SALES DEPARTMENT ON CUSTOMER RETENTION: A QUALITATIVE STUDY ON A HEALTH CARE COMPANY
}

\begin{abstract}
This paper presents a qualitative research conducted on a health care company. The aim of this research is to gather information to allow the analysis and interpretation of the return obtained after the implementation of the after-sales department. Thus, this works intends: 1. to identify the influence of the practices of the after-sales department on customer retention; 2. to verify if customers perceive the aftersales department as a relationship investment; and 3. to understand if such investment may improve the customer commitment and confidence regarding the health care company, increasing their willingness to preserve the relationship. A qualitative approach was used to reach the proposed objectives. The approach was based on interviews conducted with customers of the company. These interviews are described, analyzed and interpreted.
\end{abstract}

Key words: after-sales, customer retention, business relationship, qualitative research. 